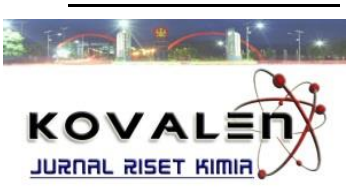

\title{
SINTESIS ETIL LAURAT DARI ASAM LAURAT MENGGUNAKAN KATALIS ASAM SULFAT PEKAT
}

\section{[SYNTHESIS OF ETHYL LAURATE FROM LAURIC ACID USING SULFURIC ACID CATALYST]}

\author{
Andi Nursyafinah $^{\left.{ }^{*}\right)}$, Nurhaeni $^{1}{ }^{1}$, Erwin Abdul Rahim ${ }^{1)}$ \\ 1) Jurusan Kimia FMIPA Universitas Tadulako, Palu \\ Diterima 14 Desember 2015, Disetujui 13 Maret 2016
}

\begin{abstract}
The aims of these research are to find out the comparison of the ratio of lauric acid molar and ethanol $(\mathrm{m} / \mathrm{v})$, the time of mixing and the best catalyst volume to produce lauric ethyl with the highest degree of esterification by using volumetric method. Synthesize of ethyl lauric from lauric acid with ethanol did by using thick sulphate acid p.a as the catalyst with comparison of lauric acid with ratio 1:3, 1:4, 1:5, 1:6, 1:7. The variation of mixing time are $1,2,3,4,5$ hour. The catalyst variation are $1,2,3,4$, and 5 $\mathrm{mL}$. This research used random variable in the confidence interval $95 \%$. The result of this research showed that the best molar lauric acid ratio and ethanol is $1: 7(\mathrm{~m} / \mathrm{v})$ and esterification degree is $59,701 \%$. The best mixing time is 5 hour, and esterification is $53,283 \%$, While catalyst volume variation is $1 \mathrm{~mL}$ with esterification degree $87,611 \%$
\end{abstract}

Keywords : Lauric Acid, Ethyl Lauric, Esterification Degree, Volumetric Method

\begin{abstract}
ABSTRAK
Penelitian ini bertujuan untuk mengetahui Perbandingan rasio molar asam laurat/etanol ( $\mathrm{m} / \mathrm{v})$, Waktu pengocokan dan Volume katalis terbaik untuk menghasilkan Etil laurat dengan derajat esterifikasi tertinggi menggunakan metode Volumetri. Sintesis etil laurat dari asam laurat dengan etanol dilakukan dengan menggunakan asam sulfat pekat p.a sebagai katalis di mana perbandingan rasio molar asam laurat/etanol $(\mathrm{m} / \mathrm{v})$ 1:3, 1:4, 1:5, 1:6, dan 1:7. Selanjutnya Variasi waktu pengocokan yaitu 1 jam, 2 jam, 3 jam, 4 jam dan 5 jam dan terakhir Variasi katalis yaitu $1 \mathrm{ml}, 2 \mathrm{ml}, 3 \mathrm{ml}, 4 \mathrm{ml}$, dan $5 \mathrm{ml}$. Penelitian menggunakan Rancangan Acak Lengkap (RAL) pada taraf kepercayaan 95\%. Hasil penelitian menunjukkan Rasio molar Asam laurat/etanol terbaik yaitu 1:7 (m/v) dengan derajat esterifikasi $59,701 \%$. Waktu pengocokan terbaik diperoleh pada waktu 5 jam dengan derajat esterifikasi $53,283 \%$. Sedangkan Variasi Volume katalis $\mathrm{H}_{2} \mathrm{SO}_{4}$ terbaik yaitu $1 \mathrm{ml}$ dengan derajat esterifikasi $87,611 \%$.
\end{abstract}

Kata Kunci : Asam Laurat, Etil Laurat, Derajat Esterifikasi, Metode Volumetri 


\section{LATAR BELAKANG}

Ester asam lemak dari berbagai minyak nabati dan lemak hewani telah dimanfaatkan dalam berbagai industri kosmetika, industri tekstil, pembuatan zat adiktif makanan, bahan zat antara industri farmasi, untuk pembuatan lemak alkohol, amida poliester dan sebagai subtitusi bahan bakar diesel (Aritonang dan Surbakti, 2004).

Salah satu jenis ester asam lemak adalah etil ester. Etil ester adalah asam lemak rantai pendek yang berperan sebagai pemberi aroma (flavor) yang mempunyai aroma buah (Yamauchi, 1996). Senyawa ester disintesis melalui reaksi esterifikasi antara asam lemak dengan alkohol menggunakan katalis asam (Fessenden, 1999 ${ }^{\mathrm{b}}$ ).

Faktor - faktor yang mempengaruhi produk etil ester yang dihasilkan dari proses esterifikasi, diantaranya adalah sebagai berikut perbandingan (rasio) molar reaktan (Arfah, 2014), waktu reaksi (Selly, dkk., 2015) dan jumlah katalis yang digunakan (Yuliani, dkk., 2008). Rasio molar yang tepat akan memberikan kondisi optimum dalam reaksi esterifikasi sehingga perolehan produk dalam jumlah maksimum dan mengurang kemungkinan bahan berlebih yang tidak bereaksi (Usman dkk., 2009). Reaksi yang berlangsung lama memerlukan energi dan biaya yang lebih besar. Waktu reaksi yang tepat akan menghemat waktu dan mengurangi biaya produksi.
Arfah (2014) melaporkan bahwa rasio molar asam laurat/ metanol menunjukkan pengaruh nyata terhadap esterifikasi, dimana rasio molar asam laurat terhadap metanol berkolerasi positif dengan penambahan volume metanol.Hasil penelitian tersebut menunjukkan rasio terbaik adalah 1:6 $(\mathrm{m} / \mathrm{v})$. Beberapa penelitian tentang waktu pengocokan reaksi esterifikasi dilaporkan bahwa waktu terbaik pada sintesis metil laurat adalah 3,5 jam dengan derajat esterifikasi sebesar 87,20\% (Arfah, 2014). Selain itu Selly dkk., (2015) melaporkan bahwa waktu reaksi esterifikasi butil oleat adalah 12 jam.

Reaksi esterifikasi dibutuhkan suatu katalis untuk mempercepat reaksi. Tanpa adanya katalis, reaksi berjalan sangat lambat karena kecepatannya tergantung pada autoprotonasi dari asam karboksilat (Kadu et al., 2011).

Menurut Firdaus dkk., mengatakan bahwa menggunakan katalis $\mathrm{H}_{2} \mathrm{SO}_{4} 1 \%$ berat dalam reaksi katalitis asam oleat dan metanol menjadi metil ester menghasilkan 95,81\%. Selain itu, Prakoso dkk., (2006) dalam Firdaus, dkk. (2013) juga telah melakukan reaksi esterifikasi pada konversi gliserol menggunakan katalis $\mathrm{H}_{2} \mathrm{SO}_{4}$ menghasilkan nilai konversi yang tinggi yaitu sebesar 99,74\%. Konversi katalis asam sulfat sebesar $5 \%$ telah dapat menyempurnakan reaksi esterifikasi asam laurat dan gliserol dan menghasilkan 
senyawa $\alpha$-monolaurin dengan rendemen 31,14\% (Widiyarti dan Hanafi, 2008).

Penelitian tentang sintesis etil laurat telah dilaporkan oleh Kasanah dkk., (2014) dimana etil laurat disintesis melalui reaksi esterifikasi alkohol dengan asam laurat menggunakan katalis $\mathrm{Zr}^{4+}$-zeolit. Kadar ester laurat yang paling banyak dihasilkan dari reaksi antara alkohol primer dengan asam laurat yang menghasilkan produk etil laurat adalah sebesar $44,44 \%$ dan butil laurat sebesar $16,62 \%$.

Berdasarkan hal tersebut diatas, maka perlu dilakukan kajian tentang reaksi esterifikasi asam laurat dengan etanol menggunakan katalis $\mathrm{H}_{2} \mathrm{SO}_{4}$ pada kondisi tertentu dapat menghasilkan etil ester dengan derajat esterifikasi tinggi.

\section{METODE PENELITIAN}

\section{Bahan dan Peralatan}

Bahan yang digunakan pada penelitian ini adalah asam laurat p.a dan etanol p.a sebagai bahan dasar dan bahan lain sebagai bahan penunjang antara lain aquadest, indikator pp, kertas saring, natrium hidroksida p.a, asam sulfat p.a dan natrium sulfat anhidrat teknis, lodium, heksana p.a, asam formiat p.a, dan dietil eter p.a.

Peralatan yang digunakan antara lain mesin kocok, erlenmeyer, sendok zat, gelas ukur, corong kaca, pipet tetes, buret, statif, klem, corong pisah, plat kromatografi lapis tipis (KLT), serta alat- alat gelas yang umum digunakan dalam laboratorium kimia.

\section{Prosedur Penelitian}

\section{Pengaruh rasio mol asam laurat/etanol (Rauf, 2010)}

Asam laurat ditimbang sebanyak 20 gram kemudian dimasukkan ke dalam erlenmeyer, selanjutnya ditambahkan etanol dengan perbandingan 1:3, 1:4, 1:5, 1:6, dan 1:7 (m/v). Kemudian ditambahkan asam sulfat pekat sebanyak $3 \mathrm{ml}$ selanjutnya dikocok diatas mesin kocok dengan kecepatan 250 rpm selama 3 jam. Campuran ditambahkan indikator phenolptalein dan dititrasi dengan larutan $\mathrm{NaOH} 3 \mathrm{~N}$ untuk menentukan derajat esterifikasinya. Hasil reaksi ditampung dicorong pisah dan didiamkan sampai terbentuk dua lapisan, kemudian lapisan bawah dibuang dan lapisan atas dicuci menggunakan aquadest sebanyak 3 kali. Etil laurat dipisahkan dari air dengan cara dilewatkan pada natrium sulfat anhidrat. Hasil reaksi dengan derajat esterifikasi yang terbaik diidentifikasi menggunakan Kromatografi Lapis Tipis (KLT).

\section{Pengaruh waktu reaksi (Rauf, 2010)}

Asam laurat ditimbang sebanyak 20 gram kemudian dimasukkan ke dalam erlenmeyer, selanjutnya ditambahkan etanol dengan perbandingan 1:7 (m/v). Kemudian ditambahkan asam sulfat pekat sebanyak $3 \mathrm{ml}$ selanjutnya dikocok diatas mesin kocok dengan kecepatan 250 rpm selama 1, 2, 3, 4, dan 5 jam. Campuran ditambahkan indikator phenolptalein dan 
dititrasi dengan larutan $\mathrm{NaOH} 3 \mathrm{~N}$ untuk menentukan derajat esterifikasinya. Hasil reaksi ditampung dicorong pisah dan didiamkan sampai terbentuk dua lapisan, kemudian lapisan bawah dibuang dan lapisan atas dicuci menggunakan aquadest sebanyak 3 kali. Etil laurat dipisahkan dari air dengan cara dilewatkan pada natrium sulfat anhidrat. Hasil reaksi dengan derajat esterifikasi yang terbaik diidentifikasi menggunakan KLT.

\section{Pengaruh Volume Katalis (Rauf, 2010)}

Asam laurat ditimbang sebanyak 20 gram kemudian dimasukkan ke dalam erlenmeyer, selanjutnya ditambahkan etanol dengan perbandingan 1:7 (m/v). Kemudian ditambahkan asam sulfat pekat sebanyak 1, 2, 3, 4, dan $5 \mathrm{ml}$ selanjutnya dikocok diatas mesin kocok dengan kecepatan 250 rpm selama 5 jam. Campuran ditambahkan indikator phenolptalein dan dititrasi dengan larutan $\mathrm{NaOH} 3 \mathrm{~N}$ untuk menentukan derajat esterifikasinya. Hasil reaksi ditampung dicorong pisah dan didiamkan sampai terbentuk dua lapisan, kemudian lapisan bawah dibuang dan lapisan atas dicuci menggunakan aquadest sebanyak 3 kali. Etil laurat dipisahkan dari air dengan cara dilewatkan pada natrium sulfat anhidrat. Hasil reaksi dengan derajat esterifikasi yang terbaik diidentifikasi dengan KLT.

\section{Penentuan Derajat Esterifikasi (Rauf, 2010)}

Derajat esterifikasi dihitung menggunakan persamaan berikut:
Derajat Esterifikasi $(\%)=\frac{(B+c)-A}{B} \times 100 \%$

Dimana :

$\mathrm{A}=$ Volume $\mathrm{NaOH} 3 \mathrm{~N}$ yang diperlukan untuk titrasi hasil reaksi $(\mathrm{ml})$

$\mathrm{B}=$ Volume $\mathrm{NaOH} 3 \mathrm{~N}$ yang diperlukan untuk titrasi asam laurat (ml)

$\mathrm{C}=$ Volume $\mathrm{NaOH} 3 \mathrm{~N}$ yang diperlukan untuk titrasi katalis asam sulfat $(\mathrm{ml})$

\section{Identifikasi dengan KLT (Rauf, 2010)}

Plat KLT yang berukuran $5 \mathrm{~cm} \times 10$ $\mathrm{cm}$ disiapkan, kemudian dibuat garis bawah dengan jarak $1 \mathrm{~cm}$ sebagai tempat penotolan dan dibuat garis atas $1 \mathrm{~cm}$ sebagai batas gerak eluen. Sampel (Etil laurat) selanjutnya ditotolkan pada plat KLT dengan menggunakan pipet mikro kemudian dimasukkan kedalam pengembang (chamber) dengan eluen campuran heksana pa; dietil eter pa; asam formiat (80: $20: 2$ ) atas dasar $\mathrm{v} / \mathrm{v} / \mathrm{v}$ (Mappiratu, 1999), dan dibiarkan bergerak hingga batas gerak eluen. Plat KLT selanjutnya dikeluarkan dari chamber, kemudian diangin-anginkan, selanjutnya dimasukkan kedalam chamber yang berisi iodium, dibiarkan hingga noda yang ada tampak.

Analisis dengan Spektrofotometer FTIR

$\mathrm{Di}$ ambil setetes etil laurat menggunakan pipet tetes lalu diletakkan di atas sel sampel yang dilewati berkas sinar inframerah. Di atur spektrumnya pada rentang bilangan gelombang 4000-600 $\mathrm{cm}^{-1}$. Dianalisis dengan spektrofotometer FT-IR. 


\section{HASIL DAN PEMBAHASAN}

\section{Rasio Mol Etanol Terhadap Asam Laurat pada Sintesis Etil Laurat}

Untuk mengetahui pengaruh rasio molar asam laurat/etanol yang menghasilkan etil laurat dengan derajat esterifikasi tertinggi maka diterapkan berbagai variasi volume etanol. Adapun waktu reaksi yang diterapkan adalah 3 jam.

Hasil yang diperoleh (Gambar 1) menunjukkan bahwa derajat esterifikasi yang dihasilkan berkolerasi positif dengan meningkatnya volume etanol yang ditambahkan. Derajat esterifikasi tertinggi adalah $59,70 \%$ diperoleh pada perlakuan dengan rasio $1: 7(\mathrm{~m} / \mathrm{v})$, sedangkan derajat esterifikasi terendah adalah 18,96\% diperoleh pada penggunaan rasio molar asam laurat terhadap etanol $1: 3(\mathrm{~m} / \mathrm{v})$.

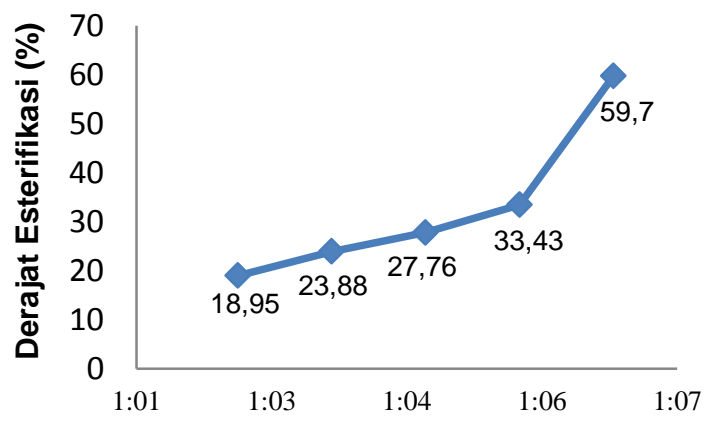

Rasio molar asam laurat/etanol (m/v)

Gambar 1 Grafik hubungan rasio molar asam laurat/etanol ( $\mathrm{m} / \mathrm{v})$ Terhadap derajat esterifikasi

Hasil yang diperoleh (Gambar 1) memperlihatkan bahwa derajat esterifikasi etil laurat mengalami peningkatan seiring dengan penambahan etanol. Hal tersebut disebabkan karena semakin banyak etanol yang ditambahkan sebagai reaktan maka produk yang dihasilkan berupa etil laurat akan semakin bertambah. Hal ini sesuai dengan prinsip Le Chatelier bahwa laju reaksi sebanding dengan konsentrasi reaktan. Karena reaksi esterifikasi adalah reaksi reversibel, maka jika diberikan alkohol berlebih dapat mengarahkan kesetimbangan kearah pembentukan ester/produk (kekanan). Untuk mencapai kesetimbangan reaksi yang lebih cepat, maka penggunaan alkohol (etanol) berlebih merupakan salah satu solusinya (Wulandari dan Septiana, 2010). Dengan kata lain terdapat volume alkohol yang optimum sehingga dihasilkan produk terbaik.

Derajat esterifikasi terbaik ( pada perlakuan yang diterapkan ) yaitu pada rasio $1: 7$ sebesar $59,70 \%$, jadi masih terdapat 40,30 \% asam laurat yang tidak teresterkan. Hasil ini belum menunjukkan keadaan optimum yang ditandai dengan nilai derajat esterifikasi yang belum turun membentuk kurva parabola. Hal tersebut juga diduga karena penggunaan etanol yang masih kurang sehingga tidak mampu mengesterkan semua asam laurat yang direaksikan (Arfah, 2014 ). Penelitian Rauf (2010) memperoleh rasio molar etanol terhadap asam kaprat dan kaprilat dengan derajat esterifikasi tertinggi (99,23\%) terdapat pada rasio $8: 1(\mathrm{v} / \mathrm{v})$.

\section{Waktu Reaksi pada Sintesis Etil Laurat}

Untuk mengetahui pengaruh waktu reaksi terhadap pembentukan etil laurat 
diterapkan variasi waktu pengocokan yang terdiri dari 5 taraf. Adapun Rasio molar asam laurat dengan etanol yang diterapkan adalah $1: 7(\mathrm{~m} / \mathrm{v})$ yang merupakan rasio molar terbaik pada perlakuan sebelumnya.

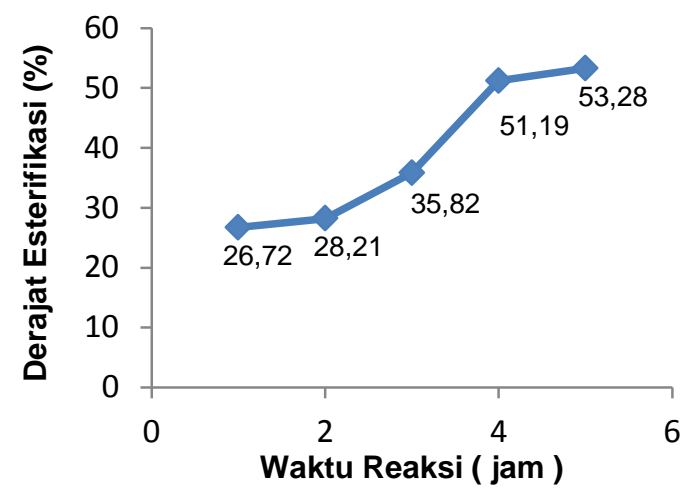

Gambar 2 Grafik hubungan waktu reaksi (jam) Terhadap derajat Esterifikasi

Hasil yang diperoleh (Gambar 2) menunjukkan bahwa derajat esterifikasi yang dihasilkan berkolerasi positif dengan bertambahnya waktu. Derajat esterifikasi tertinggi $53,28 \%$ diperoleh pada waktu 5 jam, sedangkan derajat esterifikasi terendah adalah 26,72 \% diperoleh pada waktu 1 jam. Hal ini telah sesuai dengan literatur yang menyatakan bahwa Semakin lama waktu reaksi, maka kontak antar zat semakin lama, sehingga akan menghasilkan konversi yang relatif besar (Wulandari dan Septiana, 2010). Hasil ini belum menunjukkan keadaan optimum yang ditandai dengan nilai derajat esterifikasi yang belum turun membentuk kurva parabola dengan kata lain ada waktu reaksi yang optimum sehingga dihasilkan produk yang terbaik.

\section{Volume Katalis pada Sintesis Etil Laurat}

Untuk mengetahui pengaruh volume katalis terhadap pembentukan etil laurat diterapkan perlakuan volume katalis yang terdiri dari 5 taraf. Adapun Rasio molar asam laurat dengan etanol yang diterapkan adalah $1: 7(\mathrm{~m} / \mathrm{v})$ yang merupakan rasio molar terbaik pada perlakuan sebelumnya dan waktu pengocokan yang diterapkan yaitu 5 jam yang merupakan waktu terbaik pada perlakuan sebelumnya.

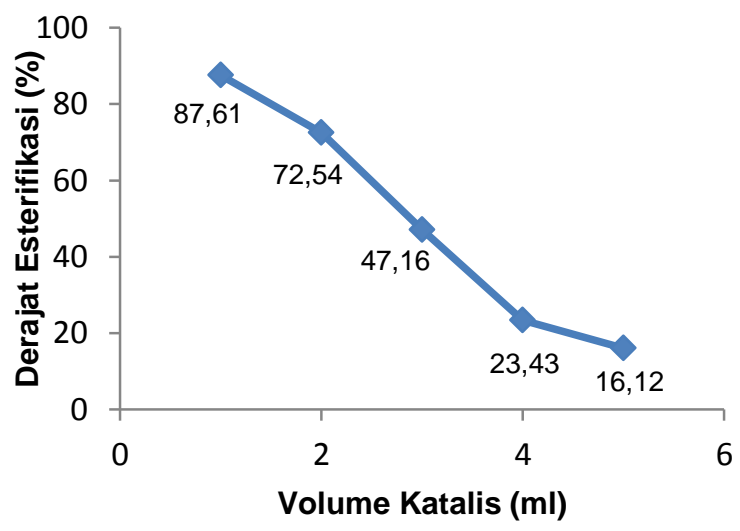

Gambar 3 Grafik hubungan Volume katalis (ml) Terhadap derajat esterifikasi

Hasil yang diperoleh Gambar 3 menunjukkan bahwa derajat esterifikasi yang dihasilkan berkolerasi negatif dengan meningkatnya volume $\mathrm{H}_{2} \mathrm{SO}_{4}$ pekat yang ditambahkan. Derajat esterifikasi tertinggi adalah $87,61 \%$ diperoleh pada perlakuan $1 \mathrm{ml} \mathrm{H}_{2} \mathrm{SO}_{4}$ pekat. Sedangkan derajat esterifikasi terendah adalah 16,12\% diperoleh pada perlakuan $5 \mathrm{ml} \mathrm{H}_{2} \mathrm{SO}_{4}$ pekat. Pada grafik (Gambar 3) terlihat bahwa derajat esterifikasi mengalami 
penurunan pada peningkatan volume katalis.

Katalis yang digunakan pada penelitian ini adalah jenis katalis asam yaitu asam sulfat $\left(\mathrm{H}_{2} \mathrm{SO}_{4}\right)$ pekat. Katalis yang sering digunakan dalam reaksi esterifikasi adalah katalis $\mathrm{H}_{2} \mathrm{SO}_{4}$ (Firdaus dkk., 2013). Katalis $\mathrm{H}_{2} \mathrm{SO}_{4}$ yang digunakan adalah katalis asam yang selain berfungsi sebagai katalis juga berfungsi sebagai penarik air. Hal ini disebabkan karena reaksi esterifikasi adalah reaksi kesetimbangan yang dapat menghasilkan air (Firdaus dkk., 2013).

Penambahan katalis asam kuat yakni asam sulfat dapat mengurangi kadar asam lemak bebas melalui protonasi oksigen karbonil asam lemak bebas dalam triliserida oleh asam sulfat. Selanjutnya, alkohol nukleofilik menyerang karbon positif, sehingga terjadi eliminasi air yang diikuti oleh penarikan $\mathrm{H}^{+}$oleh $\mathrm{H}_{2} \mathrm{O}$ hingga menghasilkan ester (Fessenden dan Fessenden, 1999b).

Derajat esterifikasi terbaik $(1 \mathrm{ml}$ $\mathrm{H}_{2} \mathrm{SO}_{4}$ ) sebesar $87,611 \%$, hal ini menunjukkan bahwa masih terdapat $12,389 \%$ asam laurat yang tidak teresterkan.Hasil penelitian sebelumnya oleh Rinaldi (2012) yang mensintesis monolaurin menggunakan katalis asam sulfat pekat menyimpulkan bahwa peningkatan konsentrasi katalis yang digunakan menurunkan derajat esterifikasi monolaurin yang dihasilkan.

Untuk mendapatkan etil laurat, maka komponen-komponen lain perlu dihilangkan, dengan mengacu pada sifat asam basa, asam laurat sisa serta katalis asam sulfat dihilangkan melalui reaksi netralisasi. Untuk mengetahui asam-asam tersebut telah ternetralisasi sempurna, digunakan indikator pp (Rauf, 2010).

Etanol termaksud senyawa organik yang bersifat polar. Dengan sifat tersebut etanol akan masuk ke sisa fasa air bersama dengan garam-garam hasil netralisasi. Penyempurnaan penghilangan etanol yang masih mungkin ada dalam fasa organik (etil laurat) dapat berlangsung melalui pencucian dengan air bebas ion atau aquadest.

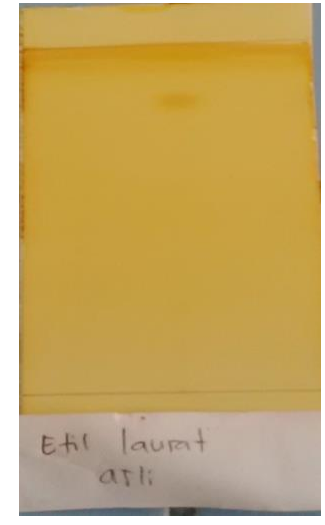

Etil Ester Standar

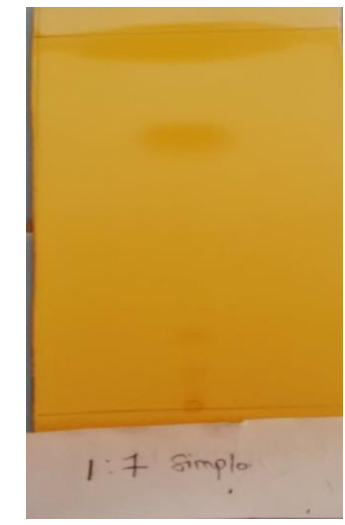

Etil Laurat Rasio Molar terbaik
Gambar 4 Hasil Kromatografi Lapis tipis (KLT)

Untuk mengetahui produk yang dihasilkan hanya produk etil laurat, dilakukan uji kemurnian menggunakan metode Kromatografi Lapis Tipis (KLT). Berdasarkan hasil analisis kualitatif menggunakan KLT dapat diketahui bahwa terdapat etil laurat pada plat KLT yang digunakan. Hal ini dapat dibuktikan dengan adanya pembanding yaitu etil 
ester asli sebagai blanko yang juga ditotolkan pada plat KLT dimana terdapat penampakan noda yang posisinya sama dengan penampakan noda etil laurat (Gambar 4).

\section{Hasil Identifikasi Gugus Fungsi}

Khasanah dkk., (2014) melaporkan bahwa hasil IR asam laurat menunjukkan adanya serapan khas gugus $\mathrm{OH}$ pada $3425,58 \mathrm{~cm}^{-1}-3016,67 \mathrm{~cm}^{-1}$. Serapan khas gugus $\mathrm{C}-\mathrm{H}$ alifatik juga muncul pada 2916,37 $\mathrm{cm}^{-1}-2854,65 \mathrm{~cm}^{-1}$ dan serapan khas gugus $\mathrm{C}=\mathrm{O}$ pada $1697,36 \mathrm{~cm}^{-1}$ serapan gugus $\mathrm{CH}_{2}$ pada $1427,32 \mathrm{~cm}^{-1}$ serta serapan khas gugus $\mathrm{C}-\mathrm{O}$ pada $941,26 \mathrm{~cm}^{-1}$. Dengan adanya literatur IR asam laurat maka dilakukan analisis IR untuk Etil laurat (Gambar 5).

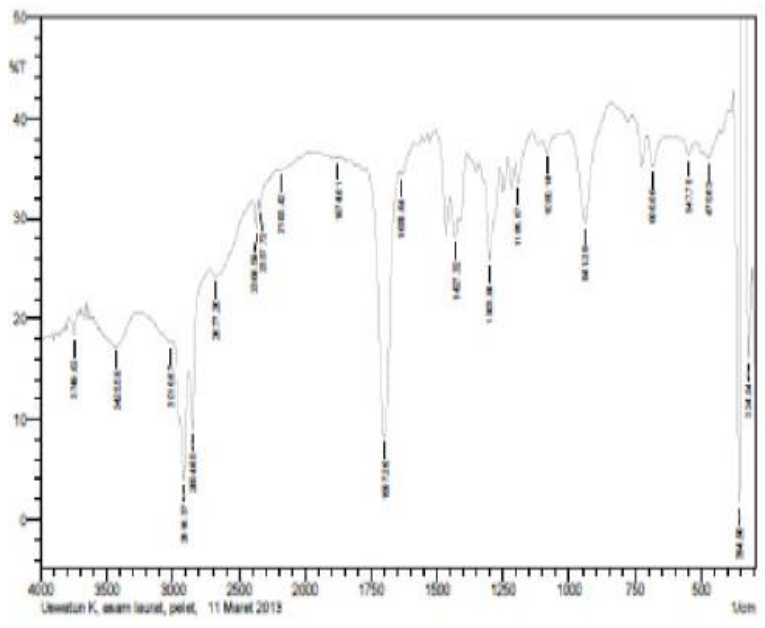

Gambar 5 Hasil FTIR asam laurat (Khasanah, dkk.,2014).

Spektrum gugus fungsional ester dilakukan dengan menggunakan spektrofotometer infra merah (Gambar 6). Pada spektrum infra merah dimana asam laurat dengan etanol dikatalis dengan asam sulfat pekat. Gugus $\mathrm{C}=\mathrm{O}$ ester terdapat pada panjang gelombang
$1737,97 \mathrm{~cm}^{-1}$, gugus $\mathrm{C}-\mathrm{H}$ alifatik terdapat pada panjang gelombang $2855,65 \mathrm{~cm}^{-1}$ hingga $2925,45 \mathrm{~cm}^{-1}$ yaitu $\mathrm{C}-\mathrm{H} \mathrm{Sp}^{3}$.

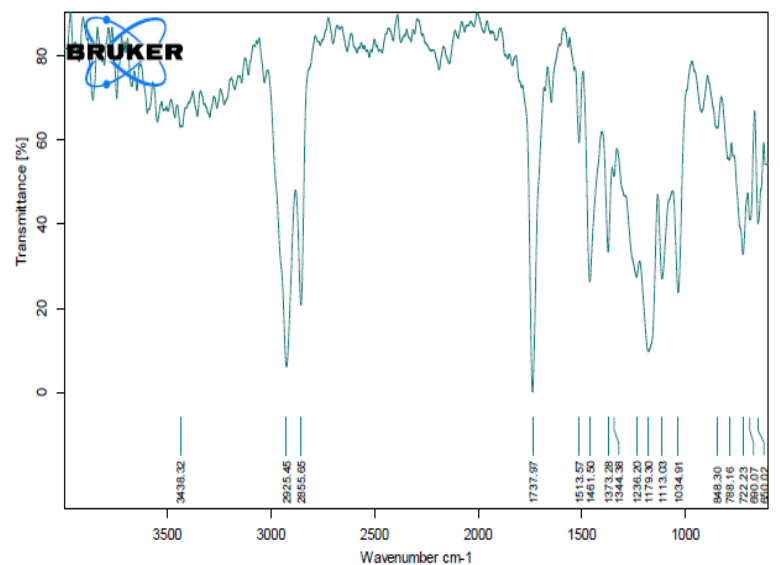

Gambar 6. Hasil FTIR Etil Laurat

Data ini diperkuat dengan pernyataan Handayani dkk., (2006) yang menyatakan bahwa spektrum FTIR sampel dengan katalis asam sulfat yang mengakibatkan terjadi beberapa perubahan pada trigliserida. Gugus $\mathrm{C}=\mathrm{O}$ terdapat pada panjang gelombang $1738,99 \mathrm{~cm}^{-1}$, gugus $\mathrm{C}=\mathrm{C}$ terdapat pada panjang gelombang 1124,87 $\mathrm{cm}^{-1}$ mengindikasikan adanya ikatan rangkap tunggal yang terdapat pada oleat, gugus $\mathrm{CH}$ terdapat pada panjang gelombang $2856,05 \mathrm{~cm}^{-1}$ hingga $2923,55 \mathrm{~cm}^{-1}$.

\section{KESIMPULAN}

Berdasarkan hasil penelitian yang telah dilakukan, dapat diambil kesimpulan bahwa rasio mol asam laurat/etanol $(\mathrm{m} / \mathrm{v})$ menghasilkan derajat esterifikasi yang berkolerasi positif dengan meningkatnya volume etanol yang ditambahkan. Demikian halnya Waktu reaksi juga menghasilkan derajat esterifikasi yang 
berkolerasi positif dengan bertambahnya waktu, sedangkan volume katalis menghasilkan derajat esterifikasi yang berkolerasi negatif dengan meningkatnya volume $\mathrm{H}_{2} \mathrm{SO}_{4}$ yang ditambahkan.

\section{DAFTAR PUSTAKA}

Aritonang H.F., Surbakti M.Br.. 2004. Separation of Lauric Acid From Coconut Oil Using Crystalization Method With Acetone Solvent. Eugenia, 10(2): 195-204

Arfah M. 2014. Optimasi Reaksi Esterifikasi Asam Laurat dengan Metanol Menggunakan Katalis Asam Sulfat. [Skirpsi]. Palu: Jurusan Kimia FMIPA UNTAD.

Fessenden dan Fessenden. 1999 ${ }^{\mathrm{a}}$. Kimia Organik Edisi Ketiga jilid 1, Jakarta:Erlangga.

Fessenden dan Fessenden. 1999 ${ }^{\mathrm{b}}$. Kimia Organik Edisi Ketiga jilid 2, Jakarta:Erlangga.

Firdaus, Usman Hanafi, Umriani Nur, Husain Dirayah M, Sukarti, Charismawan Ihsan, Rasyid $\mathrm{H}$. 2013. Efektivitas Katalis $\mathrm{AlCl}_{3}$ Dan $\mathrm{H}_{2} \mathrm{SO}_{4}$ Dalam Reaksi Esterifikasi Asam p- Kumarat. Makassar: Universitas Hasanuddin Makassar.

Handayani A, Marsudi S, Nasikin M dan Sudibandriyo M. 2006. Reaksi Esterifikasi Asam Oleat dan Gliserol Menggunakan Katalis Asam. Jurnal Sains Materi Indonesia. Edisi Khusus Oktober, 2006: 102-105.

Kadu S.S., Kulkarni S.J., Tapre, R.W., 2011. Kinetics of Esterification of $p$ Tert.butyl cyclohexanol with acetic over ion Exchange Resin Catalyst, Internasional Conference on Current Trends in Technology, NUICONE, 382 (482):1-4.

Khasanah U, Cahyono E, Sudarmin. 2014. Pengaruh Struktur Alkohol Terhadap Produk Esterifikasi Asam Laurat Terkatalisis $\mathrm{Zr}^{4+}$-Zeolit Beta. Semarang: Universitas Negeri Semarang.

Mappiratu. 1999. Penggunaan Biokatalis Dedak Padi Dalam Biosintesis
Antimikroba Monoasilgliserol dari Minak Kelapa. [Disertasi]. Bogor: Institut Pertanian Bogor.

Rauf SC. 2010. Optimasi Sintesis Etil Kaprat Dan Kaprilat Melalui Reaksi Esterifikasi. [Skripsi]. Palu: Jurusan Kimia FMIPA UNTAD.

Rinaldi A. 2012. Optimalisasi Sintesis Monolaurin Melalui Reaksi Esterifikasi Gliserol dengan Asam Laurat. [Skripsi]. Palu: Jurusan Kimia FMIPA UNTAD.

Selly M., Nirwana, Irdoni. 2015. Pengaruh Waktu Reaksi dan Rasio Molar terhadap Asam Oleat dengan Butanol pada Sintesa Plastisizer Butil Oleat. Riau: Fakultas Teknik Kimia Universitas Riau

Usman T., Ariany L., Rahmalia W., Advant R. 2009. Esterifikasi Asam Lemak dari Limbah Kelapa Sawit (Sludge Oi) Menggunakan Katalis Tawas. Indo. J. Chem., 9(3),474-478.

Widiyarti G., Hanafi M. 2008. Pengaruh Konsentrasi Katalis dan Perbandingan Molaritas Reaktan pada Sintesis Senyawa AMonolaurin, Jurnal Reaktor, 12(2):90-97

Wulandari D., Septiana O. 2010. Proses Pembuatan Biodiesel dari Dedak dan Methanol dengan Esterifikasi In Situ. [Skripsi]. Semarang: Universitas Diponegoro.

Yamauchi HT., Obata T., Amachi, Hara S., 1996. Aroma Production by Neuspora Sp. Effected By Light Irradiation. Bioschi. Bioschem. 60 (11): 1902-1904.

Yuliani F, Prismasari M, Rachmaniah O., Rachimoellah M. 2008. Pengaruh Katalis Asam $\left(\mathrm{H}_{2} \mathrm{SO}_{4}\right)$ dan Suhu Reaksi Esterifikasi Minyak Biji Karet (Hevea Brasiliesis) Menjadi Biodisel. Jurnal Teknik Kimia. 3(1) : 171-177. 